\title{
Late Twentieth-Century Warming and Variations in Cloud Cover
}

\author{
John McLean \\ Department of Physics, College of Science Technology and Engineering, James Cook University, \\ Townsville, Australia \\ Email: mcleanjoh@gmail.com
}

Received 8 August 2014; revised 6 September 2014; accepted 5 October 2014

Copyright (C) 2014 by author and Scientific Research Publishing Inc.

This work is licensed under the Creative Commons Attribution International License (CC BY).

http://creativecommons.org/licenses/by/4.0/

(c) (i) Open Access

\section{Abstract}

From 1950 to 1987 a strong relationship existed between the El Nino-Southern Oscillation (ENSO) and HadCRUT4 global average temperature anomaly, interrupted occasionally by volcanic eruptions. After 1987 the relationship diverged, with temperature anomaly increasing more than expected, but was re-established after 1997 at an offset of $\sim 0.48^{\circ} \mathrm{C}$ higher. The period of increased warming from 1987 to 1997 loosely coincided with the divergence of the global average temperature anomalies over land, which are derived from observation station recordings, and the global average anomalies in sea surface temperatures. Land-based temperatures averaged $0.04^{\circ} \mathrm{C}$ below sea temperatures for the period 1950 to 1987 but after 1997 averaged $0.41^{\circ} \mathrm{C}$ above sea temperatures. The increase in the global average temperature anomaly and the divergence of land and sea surface temperatures also coincided with two significant changes in global average cloud cover. Total cloud cover decreased during the period from 1987 to 1997 and, for most of the remainder of the period from 1984 to 2009 , decreases in low-level cloud were accompanied by increases in middle and upper level cloud. These changes can be found in both global average cloud cover and in each of the six $30^{\circ}$-latitude bands. The impact of these changes in cloud cover can account for the variations in HadCRUT4 global average temperature anomalies and the divergence between land and sea temperatures.

\section{Keywords}

Climate Change, Temperature Shift, Insolation, ENSO, ISCCP, HadCRUT4

\section{Introduction}

The latest report by the Intergovernmental Panel on Climate Change (IPCC, 2013, [1]) reports that some climate models overestimate the climate system's response to increasing greenhouse gases since 1998, in other words 
they predicted higher temperatures than those observed.

Given that models overestimate the influence of carbon dioxide it follows that the relative accuracy of the models for the period 1950 to 1997, as reported in IPCC's 4AR [2], could only occur if the models underestimated the influence of other forcings.

One forcing that might have been under-estimated is cloud cover. Variations in total solar irradiance are often discussed but not variations in cloud cover, but cloud cover impedes the flow of radiation, which in general means that it controls the amount of radiation reaching the Earth's surface during the day, and how much heat is lost during overnight cooling.

The effect of cloud cover on the net radiation budget of the earth has received much attention (e.g. Hartmann et al. [3], and Keihl, [4]), especially in the context of the zone of tropical convection, which is essentially the engine driving atmospheric circulation. In the tropical convection zone the cooling effect of increased albedo due to clouds is largely cancelled by the reduction in outgoing long wave radiation, however there is much that is not yet understood about the role of clouds.

Relevant papers include Goode and Pallé [5], who briefly discussed variations in cloud cover as part of larger paper focusing largely on variations in solar radiation. Herman et al. [6] also discussed global cloud cover but dealt mainly with surface reflectivity at $340 \mathrm{~nm}$. Kauppinen et al. [7] discussed the impact of both humidity and cloud cover on the global mean surface temperature. Eastman and Warren discuss long-term trends in cloud over sea [8] and land [9]. The former focuses on marine stratus and stratocumulus cloud cover when discussing variations in sea surface temperature and the later mentions temperature only very briefly.

This paper will attempt to address the wider issue of variation in cloud cover at all levels and in total, and whether this relates to variations in the HadCRUT4 global average temperature anomaly. Because temperature is expressed in terms of average monthly anomalies, the cloud cover data will likewise be converted to anomalies. Volcanic eruptions and the El Nino-Southern Oscillation (ENSO) are recognised influences on temperature so those influences will be identified and removed before the relationship between the residual temperature and variations cloud cover is considered.

\section{Data Sources}

This paper draws on cloud cover data from the International Satellite Cloud Climatology Project (ISCCP), at http://isccp.giss.nasa.gov/, and described in Rossow and Schiffer [10]. These data include total cloud cover as well as low, mid and upper level coverage, all of which will are used in this paper, but is only available, at the current time, for the period from 1984 to 2009.

The primary temperature data is the HadCRUT4 dataset, which is available via http://www.cru.uea.ac.uk/cru/data/temperature/.

Data for the El Nino-Southern Oscillation is the Troup Southern Oscillation Index [11] published by the Australian Bureau of Meteorology and available at http://www.bom.gov.au/climate/current/soihtm1.shtml. Under the Troup system, sustained values above +8 for at least three months usually indicate La Nina conditions and sustained values below -8 usually indicate El Nino conditions. The Troup SOI is open-ended and for the period 1950 to 2013 inclusive it averages 0.19 with a standard deviation of 10.53. The Troup SOI data is preferred to the 3-month average of sea surface temperatures in the "Nino 3.4" region (bounded by latitudes 5N-5S and longitudes $170 \mathrm{~W}-120 \mathrm{~W}$ ) because prior to 1957 data coverage of this region rarely exceeded $50 \%$ and was less than $75 \%$ for many years after, the shortfall being mainly in the western half of this region, which might have been the only portion impacted by mild ENSO events.

Data for volcanic eruptions, particular for the periods of eruption, was sourced from the Smithsonian Institution (see http://volcano.si.edu/search_eruption.cfm).

This paper uses data only since January 1950 for two reasons. The first is that the selected period corresponds to the period for which the IPCC claims that warming was largely due to human activity, meaning that the findings of this paper therefore apply to the same period.

The second reason is that prior to 1950 the coverage of HadCRUT4 temperature data for the Southern Hemisphere was below $50 \%$ in both World Wars, and fell to just $23 \%$ in 1945. After World War II Southern Hemisphere data coverage increased, with only one month during the 1950s below 50\% and after the start of 1960 it was consistently above $60 \%$.

The reliability of data during periods of low coverage is one problem but the other is that the month-to-month 
variation during low coverage is usually greater, meaning more data "noise” than during periods of greater coverage. For the decade January 1990 to December 1999, with average global coverage 83.7\%, the average absolute month-to-month variation was $0.084^{\circ} \mathrm{C}\left(\sigma=0.075^{\circ} \mathrm{C}\right)$, whereas for the decade $1940-1949$, with average coverage lower at $56.62 \%$, the variation was almost $50 \%$ higher at $0.122^{\circ} \mathrm{C}\left(\sigma=0.092^{\circ} \mathrm{C}\right)$.

\section{Analysis}

\subsection{Resolving a Residual Temperature}

The first step towards investigating the possible influence of cloud cover on the HadCRUT4 global average temperature anomaly is to establish a residual temperature anomaly from which the impacts of the ENSO and volcanic eruptions have been removed.

Large volcanic eruptions, particularly in the western Pacific, appear to have an impact on the global average temperature anomaly. Table 1 shows four volcanoes that are regarded as having a noticeable impact on the global average temperature since 1950. The displayed metrics of Volcanic Explosive Index (Lamb [12] [13] and [14]; Newhall and Self [15]) and the Dust Veil Index (Global) indicate their relative strengths.

Volcanic eruptions are a challenge when working with climate statistics. It is difficult to compare these in any simple way because the VEI scale is logarithmic. A VEI of 4 means in the range $0.1 \mathrm{~km}^{3}$ to $1 \mathrm{~km}^{3}$ of ejected tephra; a VEI of 5 is from $1 \mathrm{~km}^{3}$ to $10 \mathrm{~km}^{3}$ and so on. If an eruption rated as VEI 4 is near the lower end of that band and an eruption rated 5 is near the upper limit of that band the difference in ejected tephra, and presumably sulphides that cause cooling, could be a factor close to 100 .

In passing it is noted that the first three of the eruptions listed in Table 1 occurred in the period from 1961 to1990. The HadCRUT4 temperature dataset is derived from the variation (or "anomaly") from the long-term average temperatures for each calendar month over this same period, which means that monthly "normals" are lower than what they would be had no volcanic eruptions occurred and that the calculated anomalies are higher.

Determining the influence of volcanic eruptions on temperature is problematic. Various previous attempts have attempted to use either the Dust Veil Index (DVI) or estimates of cooling. The use the DVI is flawed because it is derived from the temperature, thus making the argument circular (Robock [16]; Bradley and Jones, [17]). Using the aerosol optical depth (AOD) to estimate cooling, such as with the technique used by Sato et al. [18], is uncertain because there appears to be no accepted factor for converting AOD into a temperature change. The other approach to estimating cooling relies on models of uncertain accuracy, which is probably inevitable when trying to calibrate them against temperature data with its short-term fluctuations, and consequently the error margins are large.

A further complexity is the potential link between volcanic eruptions and ENSO conditions (Gu and Adler [19]). El Nino events often follow volcanic eruptions in the western Pacific (Wigley [20]; Emile-Geay et al. [21]). Empirical data indicates that the cooling due to the eruption substantially counterbalanced the warming influence of the El Nino events.

Because both the cooling and warming attributable to the two phenomenon are less than expected had they occurred without the other this situation distorts any calculation of the "average" impact of such events and this distortion then impacts on the calculation of a "residual temperature" that remains after removing the influence of volcanic eruptions and the ENSO. Accordingly, the simplest interpretation of the long-term temperature records is achieved by omitting the data for the period over which major eruption caused cooling. This is unlikely to have much impact on residual temperature because the influence of volcanic eruptions is transitory with

\begin{tabular}{cccc}
\hline \multicolumn{1}{l}{ Table 1. Four major volcanic eruptions of the late twentieth century. } & & \\
\hline Volcanic Eruption & Duration & VEI & DVIG \\
\hline Agung & Feb 1963-Jan 1964 & 5 & 200 \\
Awu & Aug 1966-Oct 1966 & 4 & 800 \\
El Chichón & Mar 1982-Sep 1982 & 5 & Not Available \\
Pinatubo & Apr 1991-Sep 1991 & 6 & \\
\hline
\end{tabular}


a maximum of about three years and there is no evident trend in volcanic eruptions during the period of this study (1950-2013).

\subsection{The El Nino-Southern Oscillation (ENSO)}

The ENSO is widely recognised as having a significant impact on weather patterns both in and around the Pacific Ocean and as far away as the continents of Africa (e.g. Korecha and Barnston [22]; Ogutu et al. [23]) and Europe (e.g. Shaman and Tziperman [24]; Brönnimann et al. [25]).

The ENSO has also been found to influence global average near-surface temperature and Trenberth et al. [26] and Jones [27] found an optimum correlation between ENSO and global average temperature when using the time-lagged ENSO data from six months earlier but de Freitas and McLean [28] found the lag time varied between four and five months when data from 1950 to 1995, 1950 to 2000, 1950 to 2005 and 1950 to 2012 was considered.

Figure 1 shows the Troup SOI and HadCRUT4 global average temperature anomaly for the period from1950 to 2013 inclusive with no time lag to the SOI data. (As with other graphs in this paper a 5-month centred average is used when plotting, but monthly data is used in analyses.)

The vertical axes in Figure 1 are scaled for optimum correspondence across the period 1950-1985. The graphs show a generally close relationship, with the SOI leading the HadCRUT4 temperature data slightly, from 1950 until the late 1980s and an offset of $\sim 0.5^{\circ} \mathrm{C}$ after about 1995 .

Both signals have significant short-term fluctuations (i.e. "noise”). The SOI is more susceptible to short-term weather effects because it is derived from air pressure monitoring at just two locations, Darwin, Australia and Tahiti.

The month-to-month variation in the Troup SOI averages $6.87(\sigma=8.74)$ from 1950 to 2013 but the variation differs across the calendar year with a maximum of $9.88(\sigma=7.33)$ in May and then falls to a September low of $4.46(\sigma=3.45)$.

The month-to-month variation in HadCRUT4 data averages $0.076^{\circ} \mathrm{C}\left(\sigma=0.103^{\circ} \mathrm{C}\right)$ across the entire period, with December to March all exceeding $0.08^{\circ} \mathrm{C}$ and June to September averaging between 0.04 and $0.05^{\circ} \mathrm{C}$. Temperatures over land show a greater month-to-month variation than sea surface temperatures. The CRUTEM4 average across all months is $0.182^{\circ} \mathrm{C}\left(\sigma=0.164^{\circ} \mathrm{C}\right)$ compared to the HadSST3 average of $0.039^{\circ} \mathrm{C}$ $\left(\sigma=0.031^{\circ} \mathrm{C}\right)$

The temporary periods of divergence in Figure 1, when temperature are lower than expected from the SOI value (i.e. 1964-66, 1983 and 1991-1993) have been attributed to cooling caused by volcanic eruptions near the tropical Pacific (Agung 1963, Awu 1966, El Chichón 1982 and Pinatubo 1991) (Hansen et al. [29]; Dutton and Christy [30]; Douglass and Knox [31]). The two later periods illustrate the issues discussed earlier. Cooling due to El Chichón appears to be less than expected, with Angell $(1988,1990)$ attributing blame on the El Nino event that followed, whereas the Pinatubo eruption appears to have caused cooling and reduced the impact of the El Nino event that followed it.

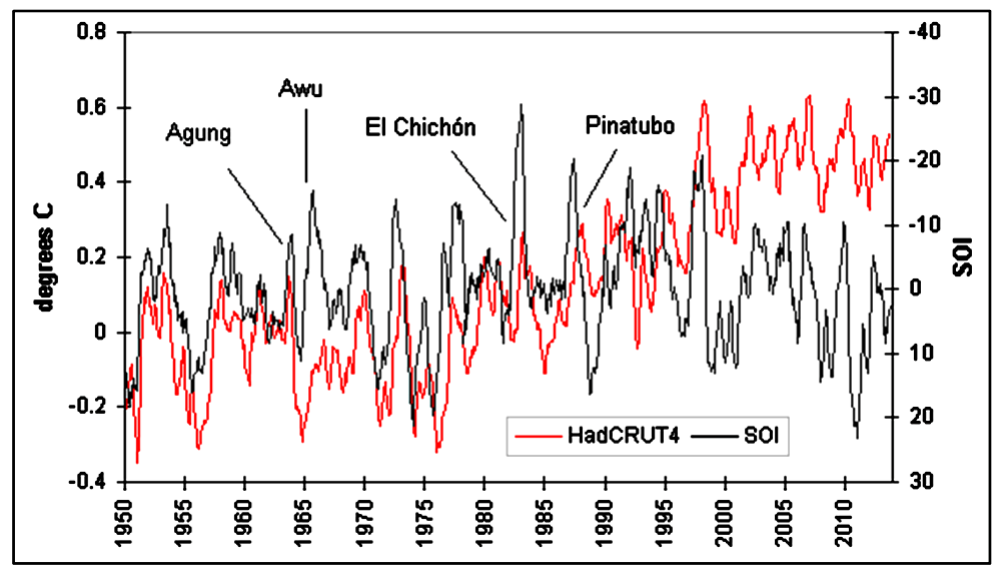

Figure 1. HadCRUT4 global average temperature anomalies and Troup SOI (5-month centred averages). 
The first step in determining the relationship between the Troup SOI and global average temperature anomaly until the late 1980's, the period of good correspondence in Figure 1, was the exclusion of the data for the periods of cooling due to volcanic eruptions. These periods are February 1963 to June 1967 (Awu eruption closely followed by Agung) and from March 1982 to September 1983 (El Chichón), which are extensions on the periods of eruptions shown in Table 1.

The second step was to find the optimum correlation between the HadCRUT4 and Troup SOI data when the latter was lagged by different numbers of months. This optimum was found to be -0.551 when using the SOI from three months earlier. The correlation appears to be reduced by two main factors, firstly the month-to-month variation (or data "noise”) discussed above and secondly possibly minor volcanoes in 1955, 1972 and 1975 (Figure 2).

After applying the three-month time lag in SOI to the 1950-1987 data with periods of eruption-driven cooling omitted, the linear equation of best fit was found to be.

$$
\text { GATA }=-0.0083 \times \text { SOI }-0.021
$$

where GATA is the HadCRUT4 global average temperature anomaly and SOI is the Troup SOI (from three months earlier).

Applying the same time lag to the 1998-2012 data, which on visual inspection appears to be of a relatively consistency in relationship, resulted in a different equation of best fit.

$$
\text { GATA }=-0.0049 \times \mathrm{SOI}+0.465
$$

The $\mathrm{R}^{2}$ values for the two equations are 0.304 and 0.196 respectively; the weaker correlation in the second period suggesting that temperature variability during that period is somehow different to the earlier period.

The 95\% percentile of the magnitude of the influence of the ENSO on global average temperature anomalies can be approximately determined by applying two standard deviations of the monthly Troup SOI data to equation one. For the period for which equation 1 was calculated, the standard deviation is 9.68 and therefore two standard deviations implies a temperature anomaly contribution of $0.16^{\circ} \mathrm{C}$.

The addition of the constants in equations 1 and 2 total almost $0.49^{\circ} \mathrm{C}$, indicating a temperature shift of approximately that amount occurred between 1988 and 1997, i.e. the intervening period between the two for which calculations were made.

Figure 3 shows the derived residual global average temperature anomaly for the period 1950-2012 after the ENSO influence, as derived from the 1950-1987 ENSO-temperature relationship, and with the periods of volcanic eruption-driven cooling omitted, i.e. the two periods as above (February 1963 to June 1967 and March 1982 to September 1983) and additionally Pinatubo (June 1991 to December 1994).

In the calculations above it was assumed a linear relationship between the SOI and HadCRUT4 global average temperature anomaly was assumed. It is however possible that the relationship varies slightly on a seasonal basis, as do temperature and prevailing winds, or in the case of regions where rainfall correlates well with the ENSO, that a sustained El Nino or La Nina event could influence the amount of surface moisture, which in turn might impact near-surface temperature until such time as the surface moisture returns to normal levels.

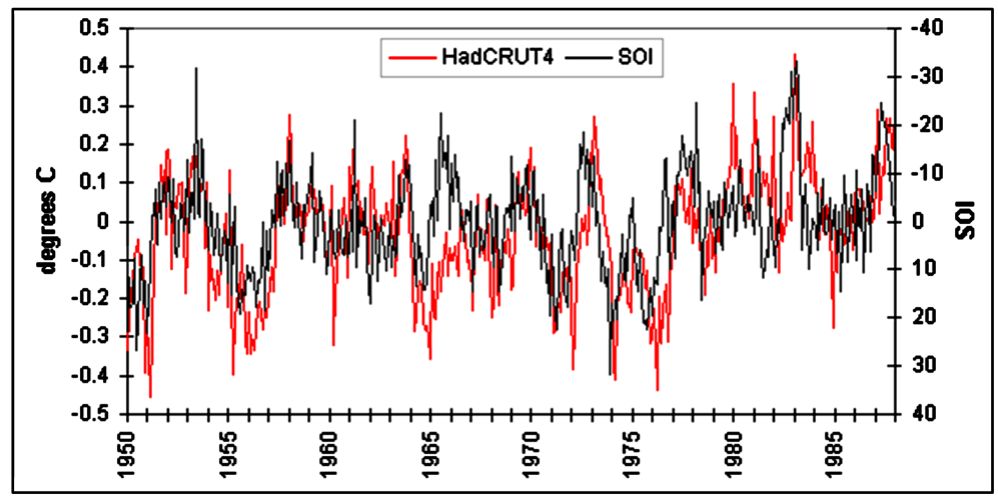

Figure 2. HadCRUT4 global average temperature anomalies and Troup SOI for 1950-1987 (monthly averages). 


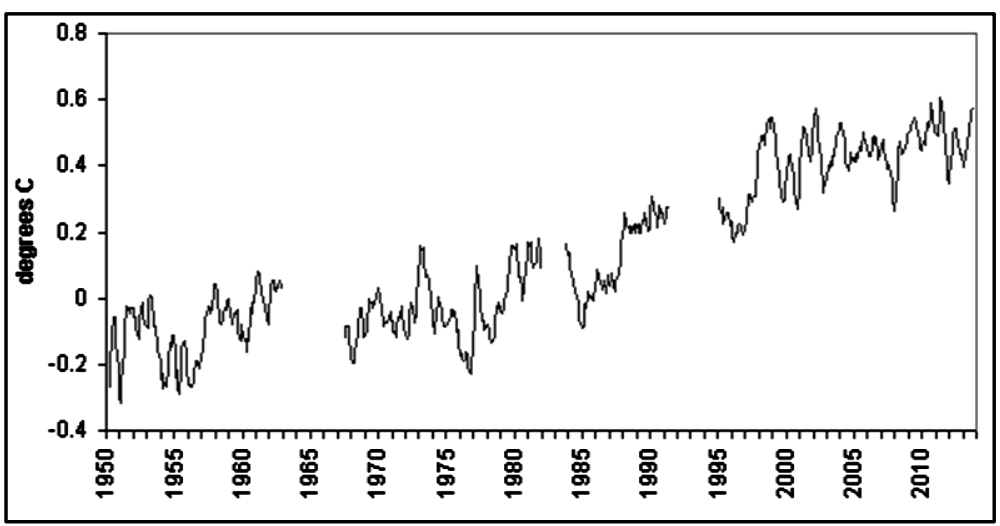

Figure 3. Residual global average temperature anomaly after removing ENSO influences and omitting periods of volcanic eruptions.

Figure 4 expands on Figure 2 by showing the number of months where the residual temperature anomaly was less than $-0.2^{\circ} \mathrm{C}$ or greater than $+0.2^{\circ} \mathrm{C}$ in each year. To put this range into context, it is slightly less than two standard deviations of month-to-month variation HadCRUT4 global average temperature anomaly described above $\left(\sigma=0.103^{\circ} \mathrm{C}\right)$.

The presence of the temperature shift in multiple temperature datasets, including near surface (HadCRUT, GISS and NCDC) and the lower tropospheric temperatures obtained from balloon-mounted instruments (RATPAC-A, UAH, and RSS) indicates that the shift is not an artefact of monitoring (e.g. technique, instrument error, number of stations, coverage) or the data processing methodology (e.g. station data adjustments). Similar shifts in the temperature-ENSO relationship are also found when the Nino 3.4 index is used, which means that the shift is not specific to the Troup SOI.

The residual global average temperature anomaly shown in Figure 3 differs from those calculated in other studies such as Trenberth et al. [26], Thompson et al. [32] and Foster and Rahmstorf [33]. Two of these three studies used temperature data prior to 1950, when hemispheric (and global) coverage was poor, and none identified the combination of post-1987 increase in temperature and post-1997 plateauing.

Further, Trenberth et al. [26] attempts to split the ENSO-temperature relationship into two periods, 1950-1978 and 1979-1998, and because the change in the relationship after 1987 wasn't identified concludes that only $0.06^{\circ} \mathrm{C}$ of the warming between 1950 and 1998 could be attributed to the ENSO. Thompson et al. [32] attempts to use sea surface temperature of the eastern Pacific cold tongue as an ENSO proxy across the period from 1900 to 2009 but data in that region is sparse prior to 1950 and particularly unreliable for determining mild ENSO conditions. Further, the ENSO relationship is derived prior to addressing the irregular cooling caused by volcanic eruptions, which were shown earlier to suppress ENSO-driven warming. Foster and Rahmstorf [33] considers only the period since 1979 and therefore largely omitted the period from 1950 to 1987 during which the global average temperature anomaly varied little.

The pattern in residual temperature anomaly of Figure 3 indicates warming from 1988 to 1997, the details of which are masked by cooling caused by the Pinatubo eruption, followed by a flattening.

\subsection{Divergence of Land and Sea Temperature Anomalies}

Perhaps associated with this pattern is that 1988 was the beginning of the divergence between the global average temperature anomalies derived from observation stations (CRUTEM4) and those derived from sea surface temperatures (HadSST3). Figure 5 shows these two anomalies using five-month centred averages but the averaging spreads the effect of brief peaks in single months.

For the period 1950 to 1986 , CRUTEM4 values exceeded HadSTT3 data by more than $0.1^{\circ} \mathrm{C}$ in $24.1 \%$ of all months and only three years had more than six months that met this condition. In contrast, since 1988 CRUTEM4 values exceeded HadSST3 data by more than $0.1^{\circ} \mathrm{C}$ in $84.3 \%$ of months, and only one year had more than six months where the condition was not met. (Unlike above, in these calculations no exclusions have been made for periods of cooling due to volcanic eruptions because both land and sea temperatures could be expected to reduce.) The average difference between CRUTEM4 and HadSST3 global averages (the former minus 


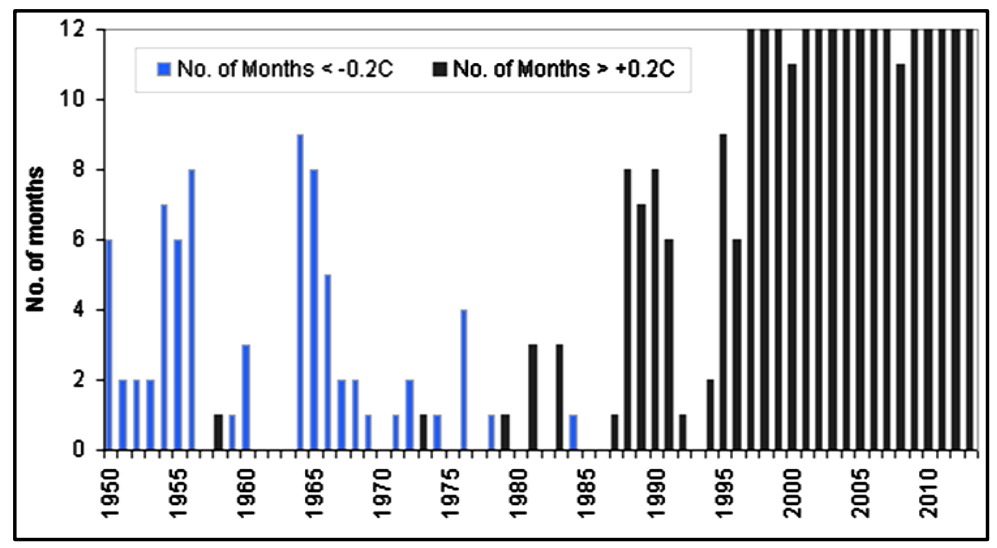

Figure 4. The number of months in each year that the residual temperature anomaly was outside the range $0^{\circ} \mathrm{C} \pm 0.2^{\circ} \mathrm{C}$.

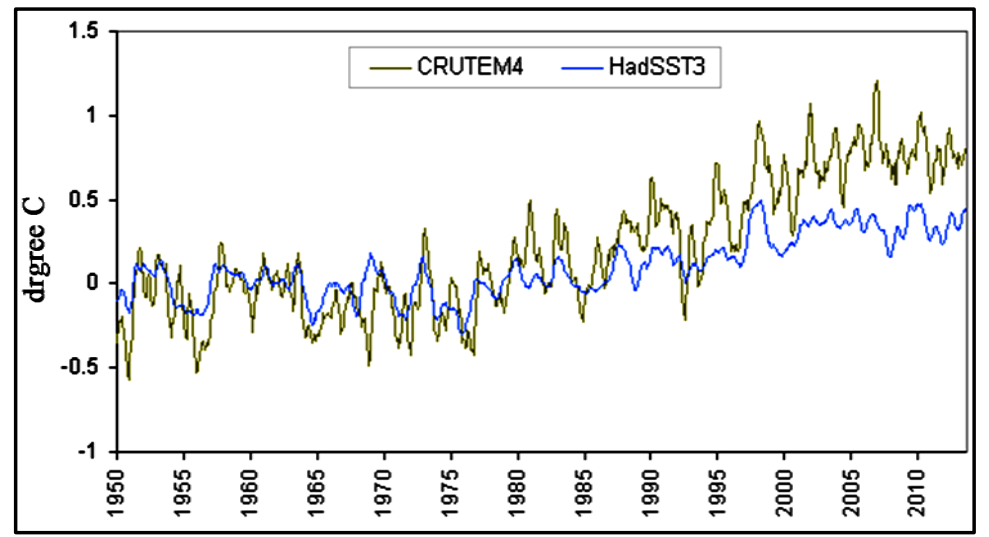

Figure 5. Global average CRUTEM4 (land-based) and HadSST2 (sea surface) temperature anomalies (5-month centred averages).

the latter) from January 1950 to December 1987 is $-0.04^{\circ} \mathrm{C}\left(\mu=0.23^{\circ} \mathrm{C}\right)$ but for the period 1998 to 2013 the average is $+0.41^{\circ} \mathrm{C}\left(\mu=0.23^{\circ} \mathrm{C}\right)$, which together indicate a shift of $0.45^{\circ} \mathrm{C}$.

The pattern of a divergence and a later offset stabilisation between these two datasets echoes the pattern in the residual temperature anomaly and the ENSO/HadCRUT4 relationship shown in Figure 1.

\subsection{Coincidental Variations in Global Average Cloud Cover}

The pattern of the residual temperature anomaly does not correspond to changes in atmospheric carbon dioxide, which has been increasing almost linearly from 1958, when monitoring began and certainly has not stabilised since 2000. The pattern is also inconsistent with other greenhouse gases, including methane, whose concentration rose from 1984 to 1999, and CFC-12, which increased from 1979 to year 2000.

The residual temperature anomaly is however consistent with two variations in cloud cover. The first is a reduction in total cloud cover, which would allow more solar insolation to strike the Earth's surface and in particular more radiation in the UV-B range; the second is a decrease in low-level cloud and increase in mid- and upper-level cloud.

As noted earlier, cloud cover data is available from the ISCCP only for the period from 1984 to 2009, which is far less than the period of available HadCRUT4 temperature data.

To compare cloud cover data with the temperature anomalies from HadCRUT4 dataset it was necessary to convert to cloud cover data first to monthly long-term averages calculated from the full span of available data, and from those averages calculate the cloud cover anomalies for each month. These anomalies were calculated for "total cloud" cover as well as for low, mid and upper level cloud.

Figure 6 shows the anomaly in global average total cloud cover and HadCRUT4 global average temperature 


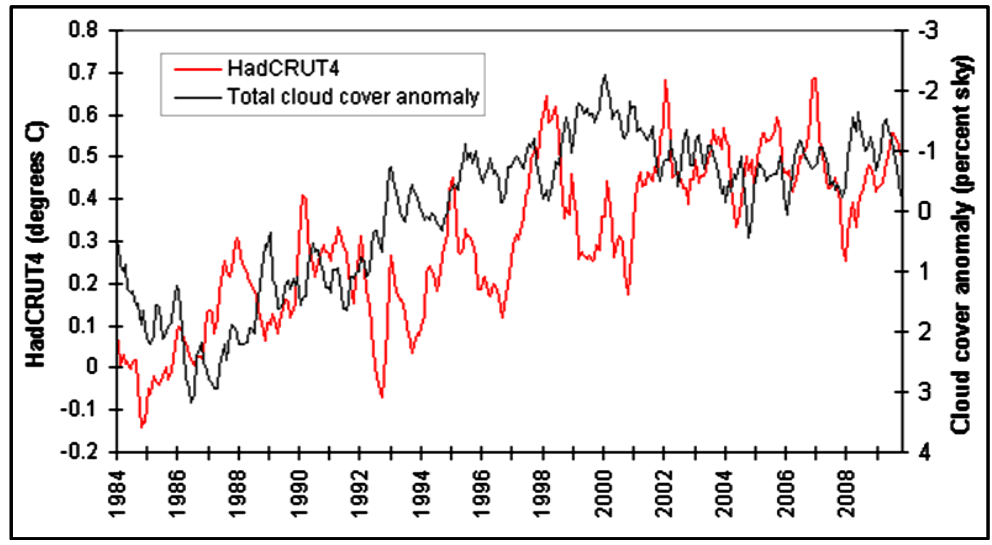

Figure 6. HadCRUT4 global average temperature anomaly and the (inverted) anomaly in total cloud cover.

anomaly with cloud cover inverted and both graph lines as three-month centred averages. The HadCRUT4 temperature anomalies fell after the eruption of Mount Pinatubo and this cooling continued for the next few years. The fall in HadCRUT4 anomalies around year 2000 was largely ENSO driven (see Figure 3). When these factors are taken into account there is general consistency of a reduction in total cloud cover as temperature anomaly increases, with cloud cover decreasing from about 1984 until year 2000 followed by a flattening out to 2009, which is the end of the available cloud cover data.

The decrease in total cloud cover anomaly is approximately 4.5 percent of sky, against the long-term average (all months 1984-2009 inclusive) of 66.4 percent of sky, which means a reduction of $6.8 \%$ of the cover.

The reduction in total cloud cover is significant in the context of the energy budget described by Trenberth $e t$ al. [34] , which indicates that cloud reflect $23 \%$ of the $341 \mathrm{Wm}^{-2}$ (i.e. $79 \mathrm{Wm}^{-2}$ ) of incoming solar radiation. The reduction in total cloud cover of $6.8 \%$ means that $5.4 \mathrm{Wm}^{-2}(6.8 \%$ of 79$)$ is no longer being reflected but acts instead as an extra forcing into the atmosphere, some of which will be lost when it adds to the longwave radiation to space. Of course clouds have many other effects on the earth's radiation budget many of which are not fully understood, but a change of $5.4 \mathrm{Wm}^{-2}$ is potentially of considerable significance.

To put this into context, the IPCC Fifth Assessment Report [1], section 8.5.2, states that the total anthropogenic radiative forcing for 2011 relative to 1750 is 2.29 [1.13 to 3.33] $\mathrm{Wm}^{-2}$ for all greenhouse gases and for carbon dioxide alone is 1.68 [1.33 to 2.03$] \mathrm{Wm}^{-2}$.

The increase in radiative forcing caused by the reduction in total cloud cover over 10 years is therefore more than double the IPCC's estimated radiative forcing for all greenhouse gases and more than three times greater than the forcing by carbon dioxide alone. Even the upper limits of the IPCC's estimates fall well short of the increase in radiative forcing caused by the reduction in total cloud cover.

Goode and Pallé [5] examined variations in Earth's albedo from 1984 to 2000 and concluded that the decrease in albedo from the late 1980s to the late 1990s caused additional shortwave forcing of $6.8 \mathrm{Wm}^{-2}$.

Herman et al. [6] determined 340nm Lambertian equivalent reflectivity of the Earth from 1979 to 2011 and found a $3.6 \% \pm 0.2 \%$ decrease in cloud reflectivity over that period, which after applying the shortwave energy balance in Trenberth et al. [34] concluded an increase of $2.7 \mathrm{Wm}^{-2}$ insolation, of which $2.3 \mathrm{Wm}^{-2}$ was absorbed by the Earth's offset slightly by increased longwave cooling. This is less than the $5.4 \mathrm{Wm}^{-2}$ described above, possibly because it focuses on $340 \mathrm{~nm}$ reflectivity, but it likewise finds a reduction in cloud cover and a consequent increase in surface temperature.

The second form of variation in cloud cover is cloud height, which is not evident from total cloud cover. Increasing cloud height is associated with an increase in the transparency of cloud and how much radiant heat passes through it. Figure 7 shows the global cloud cover anomaly at low, mid and upper levels. A general decrease in low-level cloud is evident, except for the period from 1992 to 1998, which is when firstly the Pinatubo eruption caused widespread cooling and then HadCRUT4 global average temperature recovered, accompanied by the further warming of an El Nino event.

The global average percentage sky coverages for low, mid and upper-level cloud are 27.3, 20.6 and 13.1 respectively. The reduction in low-level cloud cover, from 2.0 percent sky above average to 2.5 below, amounts to 
a change of $15 \%$. The increase in mid-level cloud, calculated in similar fashion, is $10 \%$. Considering the effect of cloud cover on both long and short wave radiation fluxes, these and the $6.8 \%$ reduction in total cloud cover are likely to be variations of considerable significance.

Figure 8 shows the anomaly in low level cloud cover with the (inverted) anomalies of the sum of mid and upper-level cloud. Across the entire period the average low cloud cover is 27 percent of sky and for the sum of mid and upper-level cloud 33.8 percent of sky. Across the calendar year low-level cloud cover varies from 23.2 percent of sky in February to 26.5 in June, and the combined mid and upper cloud varies from 38.8 in December to 33.7 in August.

The important feature of Figure 8 is that from 1988 any decrease in low-level cloud was reflected in an increase in mid and upper-level cloud (and vice versa). Between 1992 and 2002 mid and upper-level cloud reduced slightly and low-level cloud increased. From 2002 to 2009 (end of data) a reduction in low-level cloud corresponded to an increase in mid and upper-level cloud. Further, the absence of any clear shifts in the relationship between the cloud cover at each level indicates a genuine shift rather than an instrumentation issue.

\subsection{Cloud Cover Analysis by Latitude Bands}

The findings described in section 3.4 (above) were derived from global average temperature anomalies and cloud cover anomalies. A further analysis of each of six $30^{\circ}$-degree latitude bands was undertaken to determine whether the variations were widely distributed or influenced by very large variations at few locations. The contribution each band to the global averages is that the region from the equator to $30^{\circ}$ latitude covers $50 \%$ of the

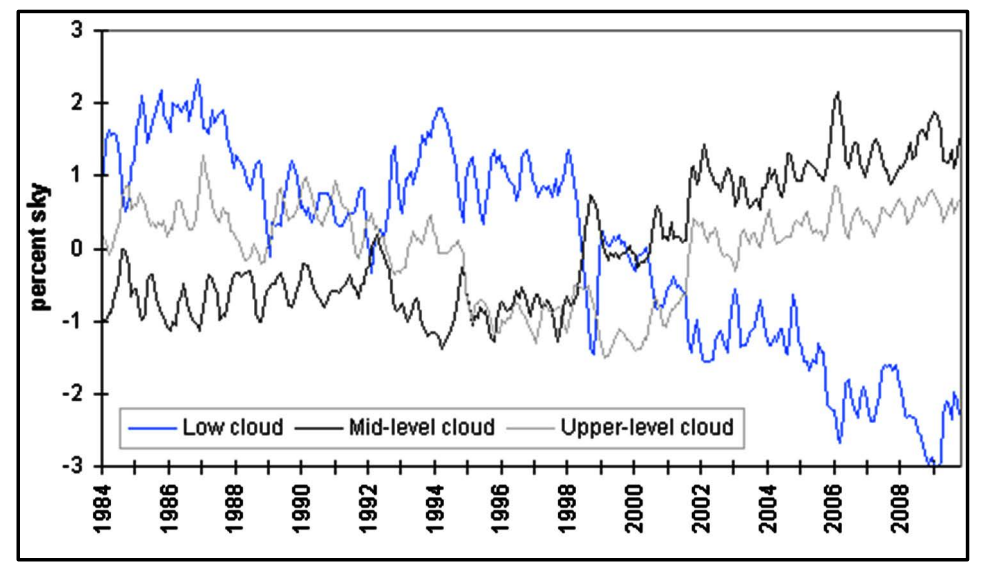

Figure 7. Global average cloud cover anomalies for low, mid and upper level cloud.

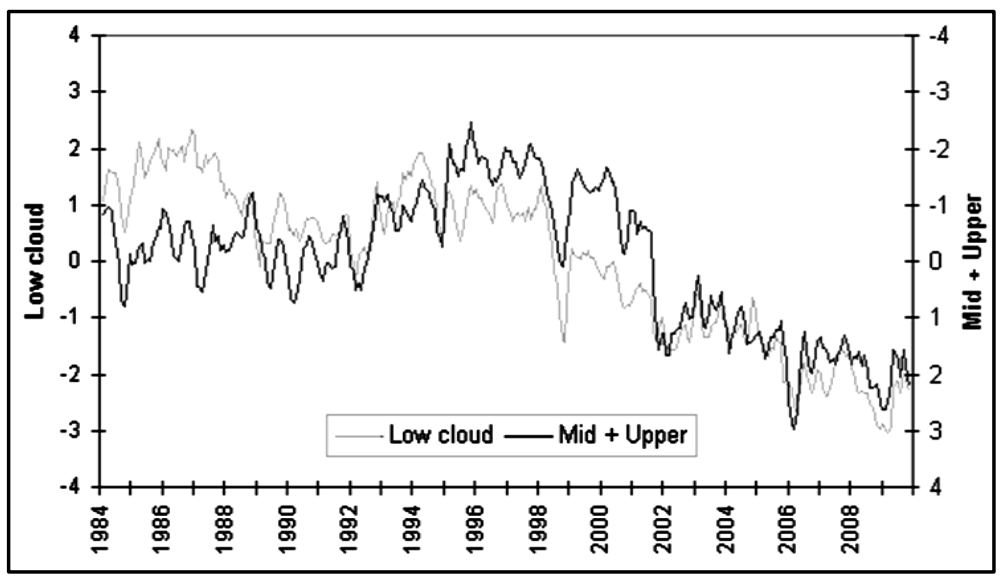

Figure 8. Anomalies in global average low-level cloud cover and the (inverted) sum of mid and upper-level cloud cover (3-month centred average). 
hemisphere, the region from $30^{\circ}$ to $60^{\circ}$ covers $36.6 \%$ and the region from $60^{\circ}$ to $90^{\circ}$ covers $13.4 \%$, so global contributions are half of each of these figures.

The mean HadCRUT4 temperature anomalies for each region are shown in Figure 9 as 7 -month centred averages. The Polar latitude bands, from $60^{\circ}$ to $90^{\circ}$ in each hemisphere, show the greatest variation in temperature both since 1950 and on a short-term basis, but neither repeats the global pattern of an obvious temperature increase from 1988 to 1997 with relative flat trends before and after. The mid-latitude band for the northern hemisphere shows greater variability than the corresponding band in the southern hemisphere, as well as a clearer
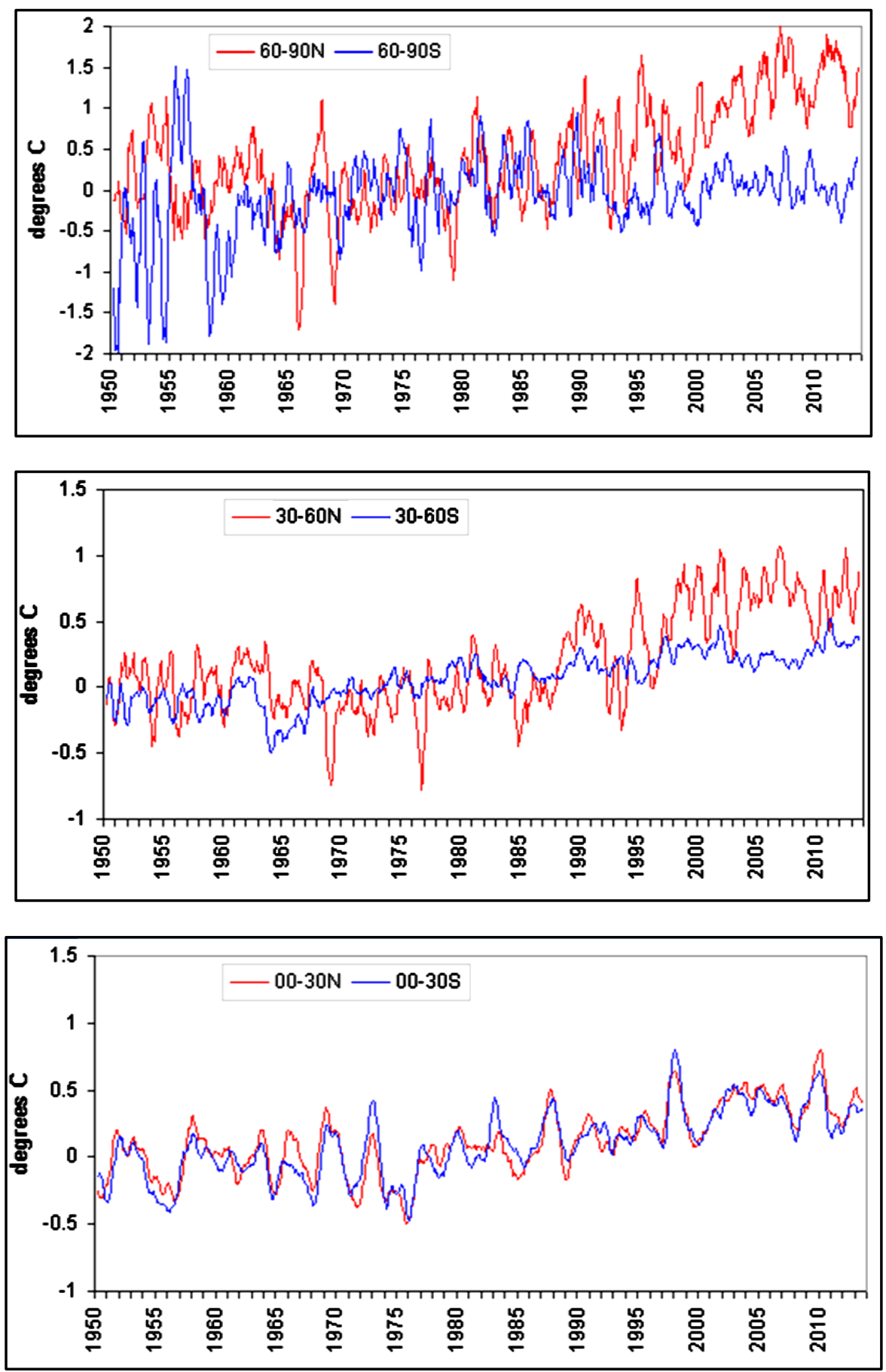

Figure 9. Average HadCRUT4 temperature anomalies for six latitude bands. 
warming period from 1988 to 1997.

The two latitude bands nearest the tropics exhibit very similar patterns in temperature anomalies, with a correlation of 0.85 on monthly data, and with both having a distinct step in 1977 when ENSO conditions swung from favouring La Nina conditions to favouring El Nino conditions.

The average of the monthly temperature anomalies for these two bands (i.e. $30^{\circ} \mathrm{N}$ to $30^{\circ} \mathrm{S}$ ) shows persistently close correlations with the Troup SOI of between -0.614 and -0.674 for ENSO time lags of zero to five months. Residual temperature anomalies can be calculated in similar fashion to that shown earlier and the pattern is almost identical to those shown in Figure 3.

The anomalies in total cloud cover for each band are shown in Figure 10. In the northern hemisphere, the polar band $\left(60^{\circ}-90^{\circ} \mathrm{N}\right)$ shows a general decrease of about 3\% sky across the period from 1987 to 2009, while the other two bands, $00^{\circ}-30^{\circ} \mathrm{N}$ and $30^{\circ}-60^{\circ} \mathrm{N}$, show decreases from about 1987 to year 2000 of about $4 \%$ sky and $6 \%$ sky respectively, and a subsequent recovery of slightly less than half those figures from 2000 to 2009. In the Southern Hemisphere only the band from $00^{\circ}$ to $30^{\circ} \mathrm{S}$ shows that pattern, the cloud cover in the other bands fluctuating but showing little trend from 1984 to 2009.

Figure 11 shows the anomalies in cloud cover at low, mid and upper levels. As for the global analysis, these show a reduction in low level cloud but an increase in mid and upper level cloud across the period for which data is available.

The correlation, for each latitude band, between low-level cloud cover and the sum of mid and upper level cloud is shown in Table 2. The correlation for the tropical bands is weak but for other bands is much stronger, where the decrease in low cloud cover is largely offset by increases at mid and upper levels.

Since 1950, temperatures have risen in all latitude bands except for the Antarctic band at $60^{\circ}-90^{\circ} \mathrm{S}$. Warming has been greatest in the Arctic band $\left(60^{\circ}-90^{\circ} \mathrm{N}\right)$, followed by $30^{\circ}-60^{\circ} \mathrm{N}$, the two tropical bands $\left(00^{\circ}-30^{\circ} \mathrm{N}\right.$ and
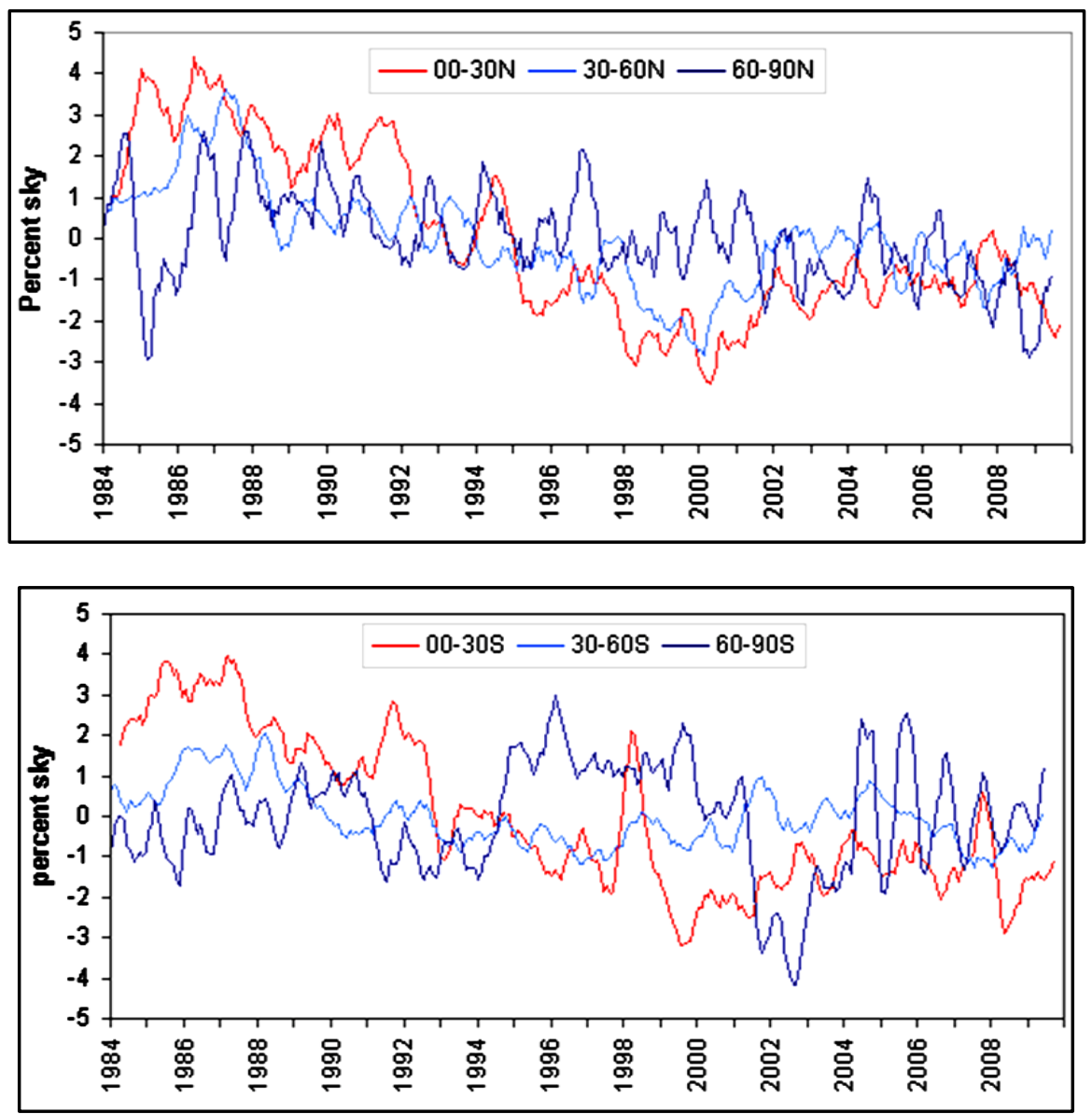

Figure 10. Anomaly in total cloud cover for each latitude band. 


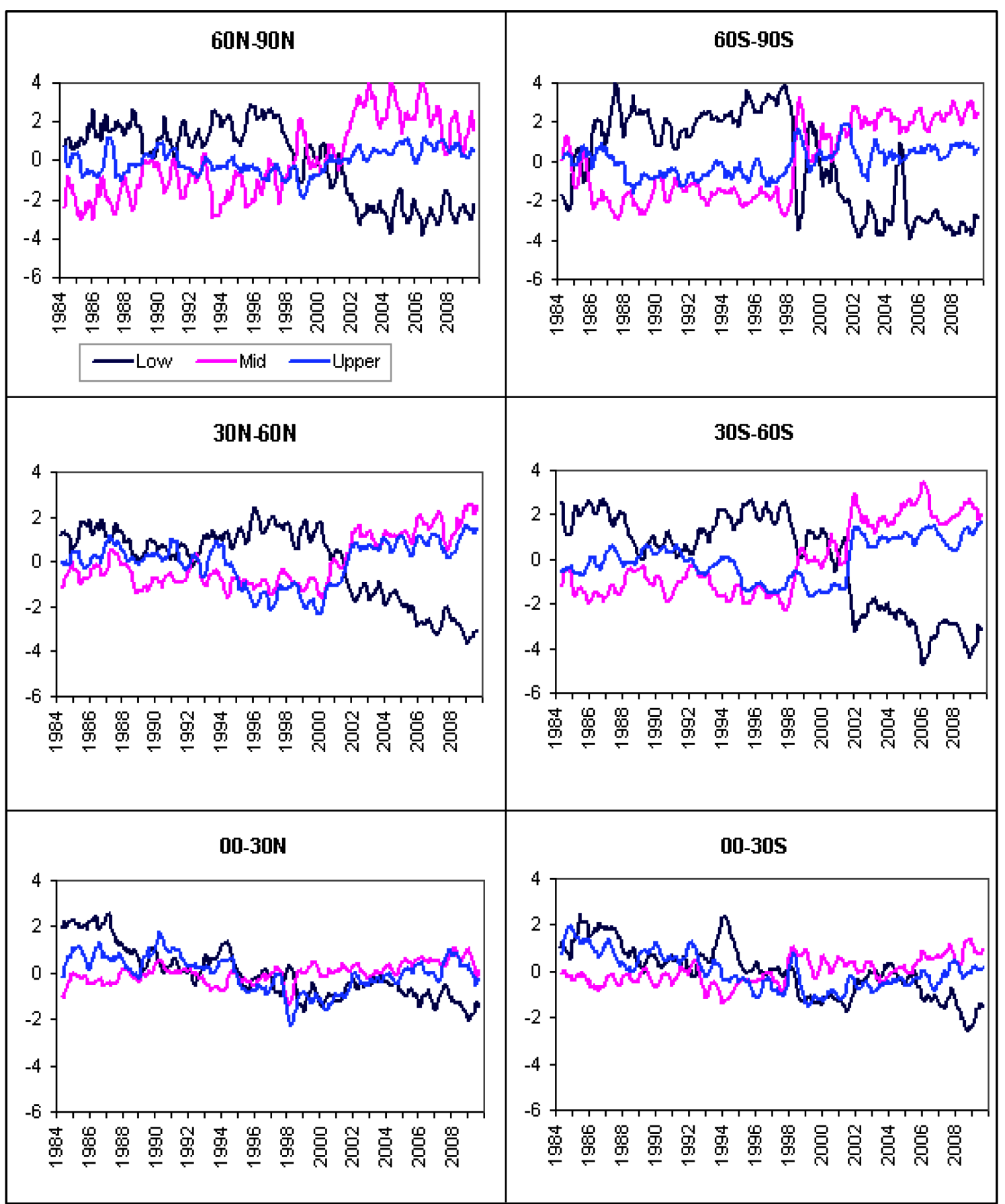

Figure 11. Anomalies in cloud cover at low, mid and upper levels for each latitude band.

$00^{\circ}-30^{\circ} \mathrm{S}$ ) and then the mid-latitude band at $30^{\circ}-60^{\circ} \mathrm{S}$.

The anomaly in total cloud cover decreased from 1987 to year 2000 in $30^{\circ}-60^{\circ} \mathrm{N}, 00^{\circ}-30^{\circ} \mathrm{N}$ and $00^{\circ}-30^{\circ} \mathrm{S}$. The Arctic band $\left(60^{\circ}-90^{\circ} \mathrm{N}\right)$ suffered a general decrease over the entire period for which data is available, 1984 to 2009 , but for the two remaining bands, $30^{\circ}-60^{\circ} \mathrm{S}$ and $60^{\circ}-90^{\circ} \mathrm{S}$, the trend in total cloud cover has been virtually flat. Changes in total cloud cover correspond well to temperature changes in each of these six latitude bands band.

Tropical bands $\left(00^{\circ}-30^{\circ} \mathrm{N}\right.$ and $\left.00^{\circ}-30^{\circ} \mathrm{S}\right)$ experienced a decrease in low-level cloud, offset rather imperfectly by an increase in mid and upper level cloud. This shift was more gradual and smaller than the similar changes 
Table 2. Mean cloud cover at each level for each latitude band and correlation between low level cloud and combined mid and upper level cloud.

\begin{tabular}{cccccc}
\hline Latitude Band & $\begin{array}{c}\text { Mean Total Cloud } \\
\text { Cover }\end{array}$ & $\begin{array}{c}\text { Mean Low Cloud } \\
\text { Cover }\end{array}$ & $\begin{array}{c}\text { Mean Mid Cloud } \\
\text { Cover }\end{array}$ & $\begin{array}{c}\text { Mean Upper Cloud } \\
\text { Cover }\end{array}$ & $\begin{array}{c}\text { Correlation } \\
\text { L to (M + U) }\end{array}$ \\
\hline $60-90 \mathrm{~N}$ & 68.429 & 18.283 & 36.537 & 6.888 & -0.754 \\
$30-60 \mathrm{~N}$ & 69.707 & 25.336 & 24.986 & 14.465 & -0.807 \\
$00-30 \mathrm{~N}$ & 58.527 & 24.495 & 14.596 & 14.305 & -0.032 \\
$00-30 \mathrm{~S}$ & 59.615 & 29.459 & 13.145 & 12.345 & -0.087 \\
$30-60 \mathrm{~S}$ & 80.852 & 36.741 & 24.930 & 13.388 & -0.951 \\
$60-90 \mathrm{~S}$ & 69.210 & 17.433 & 31.371 & 14.322 & -0.875 \\
\hline
\end{tabular}

in cloud cover at mid latitudes and high latitudes where the negative correlation between low cloud cover and the sum of the mid and upper level cloud cover is strong. In the polar bands most of the shift occurred between 1997 and 2002, after which time cloud cover trends flattened, but in the mid-latitudes the shift began later and low-level cloud was still decreasing at the end of 2009 when ISCCP data currently ends. The shift from low cloud to mid and upper level cloud will likely mean an increase in temperature but low or zero solar insolation at high latitudes in winter mean that the consequences of changes in cloud cover are more complex.

This regional analysis shows that the variations in temperature and cloud cover described by the global analysis were widespread across the planet and not due to localised extreme variations.

\section{Discussion}

This paper has shown that the variation in the global average temperature anomaly since 1950 has three distinct phases, the periods for which are 1950-1987, 1988-1997 and post 1997 respectively.

\section{(a) Phase 1 (1950-1987)}

This phase was dominated by variations driven largely by the El Nino-Southern Oscillation, interrupted at times by irregular periods of cooling caused by volcanic eruptions. It can be further split into the La Nina dominated period 1950-1976 and the El Nino dominated 1977-1987. Two La Nina events occurred during the 1950's, one of sixteen months, and no El Nino events. The first El Nino event after 1950 occurred in the latter half of 1965 and the next in 1972. Three El Nino events, two of which continued for almost 12 months, occurred during the period from 1977 to 1987, but no La Nina events.

It is often implied that the ENSO is a tri-state phenomena but it is a continuum with arbitrary thresholds for La Nina and El Nino events. A better analysis is achieved by examining the Southern Oscillation Index rather than the three defined states.

Averaging the Troup SOI over approximately equal periods across the time span shows the dominance of conditions on the La Nina side of absolutely neutral (i.e. index $=0$ ) during 1950-1976 and the dominance of conditions on the El Nino side after 1976. From 1950 to 1962 the average Troup SOI was $2.61(\sigma=9.1)$, for 1963-75 was $2.37(\sigma=10.3)$ and for 1977-1987 was $-4.62(\sigma=9.8)$. Over the period 1950 to 1987 therefore, the average Troup SOI shifted from the La Nina side of absolutely neutral to a figure almost double and on the El Nino side of absolutely neutral.

The trends in the monthly SOI data over this time appear to be related to temperature trends. From 1950 to 1976 the trend in the Troup SOI data was 0.066/year (i.e. towards La Nina) and from 1977 to 1987 was -0.0111 year, with an overall trend from 1950 to 1987 of -0.21 year. The trend in monthly HadCRUT4 global average temperature anomalies for the corresponding periods were $-0.0024^{\circ}$ year, $+0.006 \%$ year and $+0.0036^{\circ}$ \% year. Note that the temperature data used for these calculations includes data from periods when volcanic eruptions caused cooling and the precision of the figures is debatable, but an ENSO shift towards El Nino conditions and a corresponding increase in temperatures after 1977 are indicated (see also Figure 1).

(b) Phase II (1988-1997)

During this second phase the ENSO and volcanic eruptions continued to influence the temperature but after 
excluding the influence of the ENSO, the residual average global temperature anomaly was found to rise across the decade and by 1997 had reached $\sim 0.48^{\circ} \mathrm{C}$ above the 1961-90 average.

Across this decade the global average temperature anomalies from the CRUTEM3 dataset, based on data from observation stations, increasingly diverged from corresponding averages from the HadSST3 dataset whose data is derived from sea surface temperatures.

The temperature pattern for the period 1988-1997 appears to be generally consistent with the 7\% reduction in total cloud cover that occurred across the period 1987 to 1999. Applying that reduction to the influence of clouds in the energy budget described by Trenberth et al. [34] results in an increased average solar forcing at the Earth's surface of about $5 \mathrm{Wm}^{-2}$. This increase is more than double the IPCC's estimated radiative forcing from all anthropogenic emissions of greenhouse gases.

The analysis by six $30^{\circ}$ latitude bands shows a loss in total cloud cover in four of the bands but not occurring in the two southern-most bands, $30^{\circ}-60^{\circ} \mathrm{S}$ and $60^{\circ}-90^{\circ} \mathrm{S}$.

The reduction in total cloud cover during the period from 1987 to 1999 could also account for the divergence of CRUTEM4 and HadSST3 temperatures. An increase in solar radiation will pass deeper into the ocean, to about 100 metres in clear calm tropical water, and the heat disperse far more than when the same amount of radiation strikes the ground surface.

(c) Phase III (since 1997)

The third phase of the post-1950 pattern in the average global temperature anomaly is the plateauing of the anomaly after 1997.

From 1999 to 2009 total cloud cover increased slightly from its low point but at the same time there was a widespread reduction in low-level cloud that was almost matched by increases in cloud cover at middle and upper levels. This finding applies to the global average cloud cover and to latitudes $30^{\circ}$ to $90^{\circ}$ in each hemisphere.

Less opaque low-level cloud and more translucent mid and upper-level cloud meant greater solar radiation, albeit diffuse radiation, reaching the Earth's surface. This approximately coincides with both the flat trend in average global temperature anomaly and the stabilising of the difference between CRUTEM4 and HadSST3 temperature datasets although data "noise”, particularly in the former, makes confident conclusions difficult.

\section{Conclusions}

Since 1950, global average temperature anomalies have been driven firstly, from 1950 to 1987, by a sustained shift in ENSO conditions, by reductions in total cloud cover (1987 to late 1990s) and then a shift from low cloud to mid and high-level cloud, with both changes in cloud cover being very widespread.

According to the energy balance described by Trenberth et al. (2009) [34], the reduction in total cloud cover accounts for the increase in temperature since 1987, leaving little, if any, of the temperature change to be attributed to other forcings.

With ISCCP cloud cover data available only for the period from 1984 to 2009 this hypothesis should be regarded as tentative.

\section{Acknowledgements}

My thanks to Professor Peter Ridd for his support in the development of this paper.

\section{References}

[1] IPCC (2013) Climate Change 2013: The Physical Science Basis. In: Stocker, T.F., Qin, D., Plattner, G.-K., Tignor, M., Allen, S.K., Boschung, J., Nauels, A., Xia, Y., Bex, V. and Midgley, P.M., Eds., Contribution of Working Group I to the Fifth Assessment Report of the Intergovernmental Panel on Climate Change, Cambridge University Press, Cambridge, UK and New York, USA, 1535 p.

[2] IPCC (2007) Climate Change 2007: The Physical Science Basis. In: Solomon, S., Qin, D., Manning, M., Chen, Z., Marquis, M., Averyt, K.B., Tignor, M. and Miller, H.L., Eds., Contribution of Working Group I to the Fourth Assessment Report of the Intergovernmental Panel on Climate Change, Cambridge University Press, Cambridge, UK and New York, USA, 996 p.

[3] Hartmann, D.L., Moy, L.A. and Fu, Q. (2001) Tropical Convection and the Energy Balance at the Top of the Atmosphere. Journal of Climate, 14, 4495-4511. http://dx.doi.org/10.1175/1520-0442(2001)014<4495:TCATEB>2.0.CO;2

[4] Keihl, J.T. (1994) On the Observed near Cancellation between Longwave and Shortwave Cloud Forcing in Tropical 
Regions. Journal of Climate, 7, 559-565. http://dx.doi.org/10.1175/1520-0442(1994)007<0559:OTONCB>2.0.CO;2

[5] Goode, P.R. and Pallé, E. (2007) Shortwave Forcing of the Earth's Climate: Modern and Historical Variations in the Sun's Irradiance and the Earth's Reflectance. Journal of Atmospheric and Solar-Terrestrial Physics, 69, 1556-1568. http://dx.doi.org/10.1016/j.jastp.2007.06.011

[6] Herman, J., DeLand, M.T., Huang, L.-K., Labow, G., Larko, D., Lloyd, S.A., Mao, J., Qin, W. and Weaver, C. (2012) A Net Decrease in the Earth's Cloud, Aerosol, and Surface 340 nm Reflectivity during the Past 33 yr (1979-2011). Atmospheric Chemistry and Physics, 13, 8505-8524. http://dx.doi.org/10.5194/acp-13-8505-2013

[7] Kauppinen, J., Heinonen, J. and Malmi, P. (2014) Influence of Relative Humidity and Clouds on the Global Mean Surface Temperature. Energy and Environment, 25, 389-400. http://dx.doi.org/10.1260/0958-305X.25.2.389

[8] Eastman, R. and Warren, S.G. (2011) Variation in Cloud Cover and Cloud Types over the Ocean from Surface Observations, 1954-2008. Journal of Climate, 24, 5914-5934. http://dx.doi.org/10.1175/2011JCLI3972.1

[9] Eastman, R., Warren, S.G. and Hahn, C.J. (2013) A 39-yr Survey of Cloud Changes from Land Stations Worldwide 1971-2009: Long-Term Trends, Relation to Aerosols, and Expansion of the Tropical Belt. Journal of Climate, 26, 1286-1303. http://dx.doi.org/10.1175/JCLI-D-12-00280.1

[10] Rossow, W.B. and Schiffer, R.A. (1991) ISCCP Cloud Data Products. Bulletin of the American Meteorological Society, 72, 2-20. http://dx.doi.org/10.1175/1520-0477(1991)072<0002:ICDP>2.0.CO;2

[11] Troup, A.J. (1965) The “Southern Oscillation”. Quarterly Journal of the Royal Meteorological Society, 91, $490-506$. http://dx.doi.org/10.1002/qj.49709139009

[12] Lamb, H.H. (1970) Volcanic Dust in the Atmosphere; with a Chronology and Assessment of Its Meteorological Significance. Philosophical Transactions of the Royal Society of London, Series A, 266, 425-533. http://dx.doi.org/10.1098/rsta.1970.0010

[13] Lamb, H.H. (1977) Supplementary Volcanic Dust Veil Assessments. Climate Monitor, 6, 57-67.

[14] Lamb, H.H. (1983) Update of the Chronology of Assessment of the Volcanic Dust Veil Index. Climate Monitor, 12, 79-90.

[15] Newhall, C.G. and Self, S. (1982) The Volcanic Explosivity Index (VEI) An Estimate of Explosive Magnitude for Historical Volcanism. Journal of Geophysical Research: Oceans, 87, 1231-1238. http://dx.doi.org/10.1029/JC087iC02p01231

[16] Robock, A. (1981) A Latitudinally Dependent Volcanic Dust Veil Index, and Its Effect on Climate Simulations. Journal of Volcanology and Geothermal Research, 11, 67-80. Http://dx.doi.org/10.1016/0377-0273(81)90076-7

[17] Bradley, R.S. and Jones, P.D. (1992) Records of Explosive Volcanic Eruptions over the Last 500 Years. In: Bradley, R.S. and Jones, P.D., Eds., Climate Since A.D. 1500, Routledge, London, 606-622.

[18] Sato, M., Hansen J.E., McCormick, M.P. and Pollak J.B. (1993) Stratospheric Aerosol Optical Depths, $1850-1990$. Journal of Geophysical Research: Atmospheres, 98, 22987-22994. http://dx.doi.org/10.1029/93JD02553

[19] Gu, G. and Adler, R.F. (2011) Precipitation and Temperature Variations on the Interannual Time Scale: Assessing the Impact of ENSO and Volcanic Eruptions. Journal of Climate, 24, 2258-2270. http://dx.doi.org/10.1175/2010JCLI3727.1

[20] Wigley, T.M.L. (2000) ENSO, Volcanoes and Record-Breaking Temperatures. Geophysical Research Letters, 24, 4101-4104. http://dx.doi.org/10.1029/2000GL012159

[21] Emile-Geay, J., Seager, R., Cane, M.A., Cook, E.R. and Haug, G.H. (2008) Volcanoes and ENSO over the Past Millennium. Journal of Climate, 21, 3134-3148. http://dx.doi.org/10.1175/2007JCLI1884.1

[22] Korecha, D. and Barnston, A.G. (2007) Predictability of June-September Rainfall in Ethiopia. Monthly Weather Review, 135, 628-650. http://dx.doi.org/10.1175/MWR3304.1

[23] Ogutu, J.O., Piepho, H.P., Dublin, H.T., Bhola, N. and Reid, R.S. (2008) El Niño-Southern Oscillation, Rainfall, Temperature and Normalized Difference Vegetation Index Fluctuations in the Mara-Serengeti Ecosystem. African Journal of Ecology, 46, 132-143. http://dx.doi.org/10.1111/j.1365-2028.2007.00821.x

[24] Shaman, J. and Tziperman, E. (2011) An Atmospheric Teleconnection Linking ENSO and Southwestern European Precipitation. Journal of Climate, 24, 124-139. http://dx.doi.org/10.1175/2010JCLI3590.1

[25] Brönnimann, S., Xoplaki, E., Casty, C., Pauling, A. and Luterbacher, J. (2007) ENSO Influence on Europe during the Last Centuries. Climate Dynamics, 28, 181-197. http://dx.doi.org/10.1007/s00382-006-0175-z

[26] Trenberth, K.E., Caron, J.M., Stepaniak, D.P. and Worley, S. (2002) Evolution of El Niño-Southern Oscillation and Global Atmospheric Surface Temperatures. Journal of Geophysical Research: Atmospheres, 107, AAC501-AAC517. http://dx.doi.org/10.1029/2000JD000298

[27] Jones, P.D. (1989) The Influence of ENSO on Global Temperatures. Climate Monitor, 17, 80-89. 
[28] de Freitas, C.R. and McLean, J.D. (2013) Update of the Chronology of Natural Signals in the Near-Surface Mean Global Temperature Record and the Southern Oscillation Index. International Journal of Geosciences, 4, 234-239. http://dx.doi.org/10.4236/ijg.2013.41A020

[29] Hansen, J.E., Wang, W.C. and Lacis, A.A. (1978) Mount Agung Eruption Provides Test of Global Climate Perturbation. Science, 199, 1065-1068. http://dx.doi.org/10.1126/science.199.4333.1065

[30] Dutton, E.G. and Christy, J.R. (1992) Solar Radiative Forcing at Selected Locations and Evidence for Global Lower Tropospheric Cooling Following the Eruptions of El Chichon and Pinatubo. Geophysical Research Letters, 19, 23132316. http://dx.doi.org/10.1029/92GL02495

[31] Douglass, D.H. and Knox, R.S. (2005) Climate Forcing by the Volcanic Eruption of Mount Pinatubo. Geophysical Research Letters, 32, Published Online. http://dx.doi.org/10.1029/2004GL022119

[32] Thompson, D.W.J., Wallace, J.M., Jones, P.D. and Kennedy, J.J. (2009) Identifying Signatures of Natural Climate Variability in Time Series of Global-Mean Surface Temperature: Methodology and Insights. Journal of Climate, 22, 6120-6141. http://dx.doi.org/10.1175/2009JCLI3089.1

[33] Foster, G. and Rahmstorf, S. (2011) Global Temperature Evolution 1979-2010. Environmental Research Letters, 6, Article ID: 044022. http://dx.doi.org/10.1088/1748-9326/6/4/044022

[34] Trenberth, K.E., Fasulo, J.T. and Keihl, J. (2009) Earth’s Global Energy Budget. Bulletin of the American Meteorological Society, 90, 311-323. http://dx.doi.org/10.1175/2008BAMS2634.1 
Scientific Research Publishing (SCIRP) is one of the largest Open Access journal publishers. It is currently publishing more than 200 open access, online, peer-reviewed journals covering a wide range of academic disciplines. SCIRP serves the worldwide academic communities and contributes to the progress and application of science with its publication.

Other selected journals from SCIRP are listed as below. Submit your manuscript to us via either submit@scirp.org or Online Submission Portal.
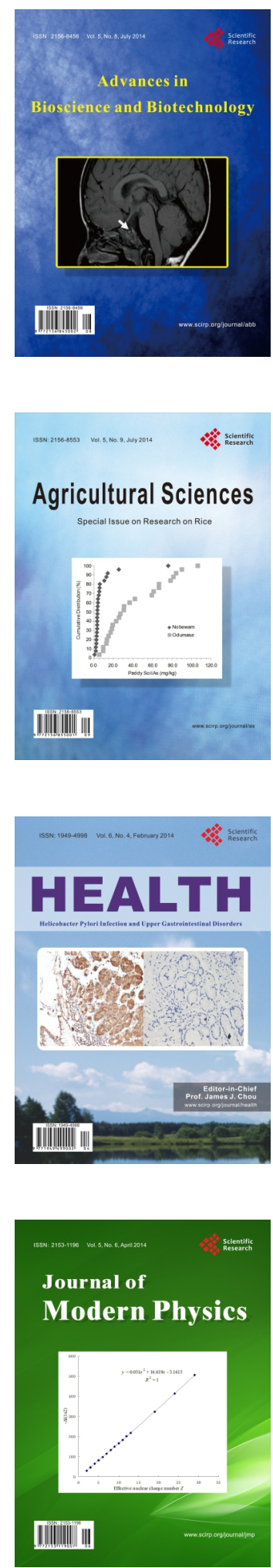
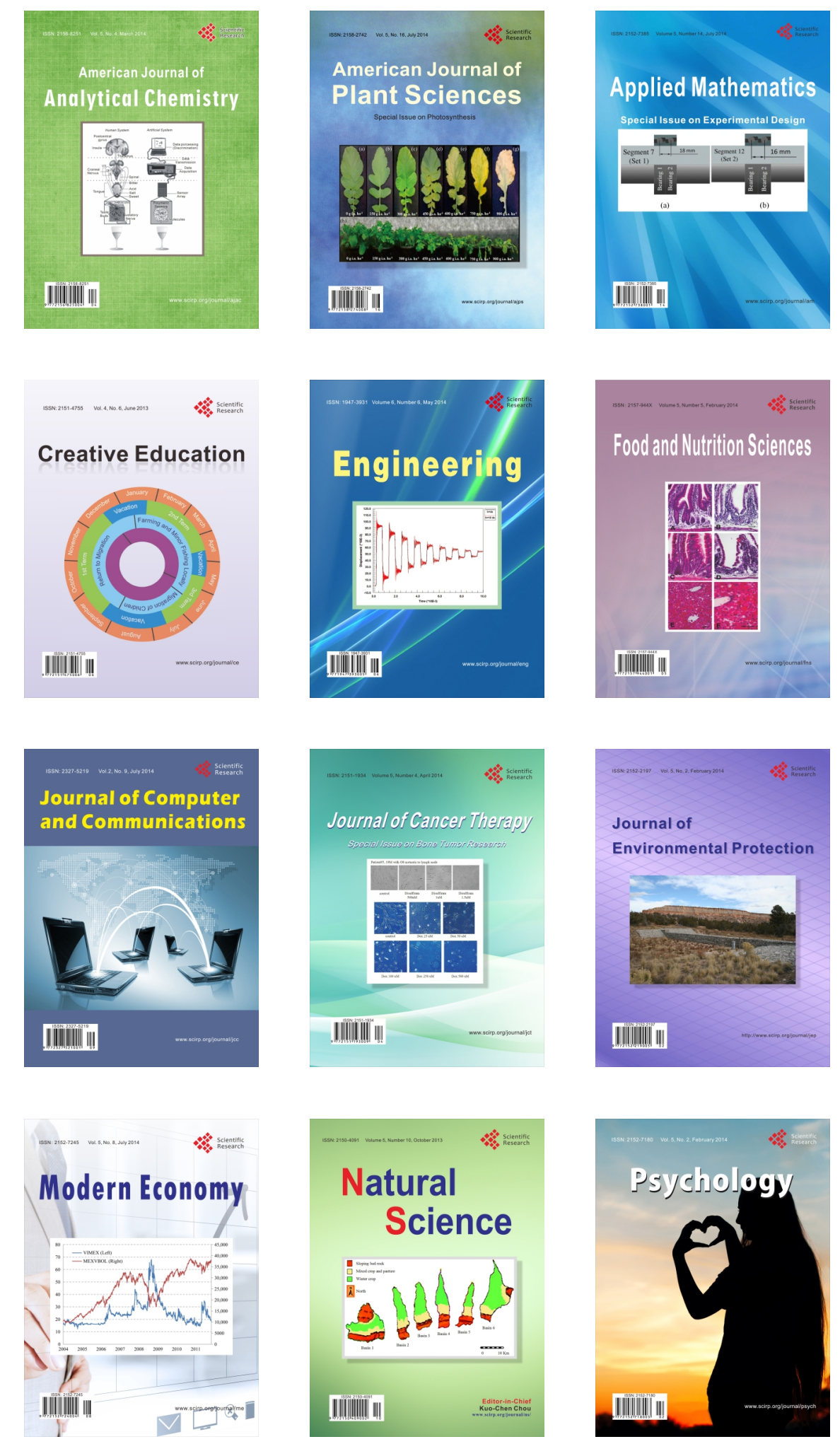